Chapter 2

\title{
Mental Health - An Issue Neglected by European Public Health Systems?
}

\author{
Denise Zak \\ Additional information is available at the end of the chapter \\ http://dx.doi.org/10.5772/59138
}

\section{Introduction}

Mental disorders comprise a wide spectrum of illnesses that are characterized by tremendous disabilities and impairments. In addition to this loss of quality of life for patients, mental disorders entail high costs for public health systems. In recent years, there has been an increasing amount of literature on the economics of mental disorders. Overall, there seems to be evidence indicating a notable prevalence of mental disorders and a sizeable treatment gap, expressed in a large number of patients suffering from one (or more) mental disorder(s) who have been treated insufficiently. The question arises whether the unmet need is due to a general lack of awareness within (national) health and social care systems and a kind of misallocation of resources (supply-side problem) or if the utilization of services is hindered by stigma or exclusion (demand-side problem).

Epidemiologic data is scarce, which is presumably the reason why the suffering of the patients as well as the significance of the economic burden are underestimated. Reliable estimates of costs and benefits associated with mental disorders are needed to ensure health care planning and financing.

The aim of this chapter is to provide a comprehensive review of literature on this subject. The economics of the most frequent and most burdensome mental disorders are discussed. Therefore only the cost-of-illness studies on affective disorders, generalized anxiety disorder, schizophrenia and alcoholism are taken into consideration. In the light of demographic developments reference is also made to mental disorders of the elderly (i.e. dementias). Mental disorders which begin in childhood and adolescence (i.e. hyperkinetic disorders, autism) are also outlined to point out the importance of prevention. Accordingly, both age cohorts will increasingly challenge health care systems. In this chapter the range of costs and the meth- 
odological constraints of different cost estimates at the European level are discussed in detail as well as the different kinds of challenges for the Austrian health care system.

Only those publications published from 1994-2014 were included because of the changes in diagnostic criteria. Within this timeframe it can be assumed that diagnoses are based on the ICD-10 and DSM-IV criteria respectively, which enhances comparability between the studies analyzed. Regarding the spatial focus, the current 28 member countries of the European Union are part of the analysis, but special attention is paid to the (limited) data available in Austria.

\section{Health economics and mental health}

In most OECD countries mental health care is insufficiently integrated in the health care system, which is also reflected in the expenditures for mental health [1]. To date, various methods have been developed and introduced to measure the economic impact of ill-health. With a focus on mental health, the cost-of-illness studies have gained interest in the past decades. In general, cost-of-illness studies provide monetary estimates for the economic burden associated with a disease [2]. Thus, information on the allocation of resources and on the relative importance of a disease can be used for further in-depth analyses or (international) comparison.

Generally, the relevant costs are classified into direct, indirect and intangible costs. Direct costs are the expenses for medical goods and services. Often direct costs are subdivided into direct medical and non-medical costs, where the latter refer to all associated services.

Basically, two broad approaches can be distinguished to assess direct costs, i.e. top down and bottom up. Costs in top down analyses are calculated based on aggregated national data and statistics to obtain an estimate of the (health) economic significance of an illness. In contrast, bottom up analyses estimate costs on the basis of resource consumption at the level of the individual patient.

Indirect costs refer to productivity losses owing to a specific illness. There are two approaches to assess indirect costs: the human capital and the friction costs methods. Within the evaluation of mental disorders, the human capital approach is more common and recommended [3]. The core of this method is the assumption that an economy's potential productivity is the sum of the output produced by its population in working age over an expected lifetime. In the case of early retirement or premature death, all productivity losses are projected for the whole life span, resulting in high indirect costs for chronic illnesses. [4]

Suffering, pain and reduced quality of life are also relevant in research on mental health and are summarized as intangible costs. In particular, quantification and monetarization are aggravated by methodological difficulties.

Throughout (mental) health economic studies, the measurement and definition of costs are not consistent. For example, the costs of informal care (i.e. care by members of the family and friends) are often assigned to indirect costs, but can also be assigned to direct non-medical 
costs. Costs associated with suicide, which are of particular relevance in mental disorders, are hardly taken into account owing to manifold difficulties in valuation.

\section{Epidemiology of mental disorders in Europe}

The most comprehensive work providing the first epidemiologic and economic data on mental disorders in the European Union is a compilation of recent studies: in a comprehensive review on the costs of disorders of the brain the total costs of 12 selected disorders were estimated at $€ 386$ billion, of which $€ 240$ billion account for mental disorders alone (2004 prices, dementia excluded) [5]. Only those studies including the cost-of-illness data published in the EU-25 member countries and Norway, Switzerland as well as Iceland were selected. In addition, studies based on clinical trials, reviews, quality of life studies and studies dealing with specific treatment forms were excluded. Direct healthcare costs, direct non-medical costs and indirect costs for the following 12 disorders were estimated: affective disorders (depression, bipolar disorders), psychotic disorders (schizophrenia), anxiety disorders (panic disorders, social phobia, special phobias, agoraphobia, generalized anxiety disorder, obsessive compulsive disorder), addiction (illicit drugs, alcohol), dementia, brain tumour, trauma, stroke, epilepsy, multiple sclerosis, Parkinson's disease, migraine and other headaches. The prevalence of these disorders in 2004 amounted to $27 \%$ of the total population covered in the study.

Based on this analysis, a follow-up study was initiated. Using a multi-method approach including literature research, the analysis of epidemiologic data and country-specific expert surveys, the 12 month prevalence of the disorders included in the first report [6] as well as 14 new disorders for EU-27 plus Norway, Switzerland und Iceland was estimated [7]. Additionally the age group covered was extended to the major mental disorders for children and adolescents (2-17), adults (18-65) and elderly (65+years). Within this study, substance use disorders (alcohol dependence, opioid dependence, cannabis dependence), psychotic disorders (schizophrenia, other psychotic disorders), mood disorders (bipolar disorders, major depression), anxiety disorders (posttraumatic stress disorder, obsessive-compulsive disorder, generalized anxiety disorder, social phobia, specific phobias, agoraphobia, panic disorder), somatoform disorders, eating disorders (anorexia nervosa, bulimia nervosa), childhood and adolescence disorders (pervasive developmental disorders/autism, hyperkinetic disorders/ ADHD, conduct disorders), personality disorders (dissocial personality disorder, emotionally unstable personality disorder), sleep disorders (non-organic insomnia, hypersomnia, narcolepsy, sleep apnoea), mental retardation and dementias were ascertained.

As a result, it was estimated that each year $38.2 \%$ of the EU population would be affected by a mental disorder, whereas the most frequent disorders are anxiety disorders (14\%), insomnia (7\%) and major depression (6.9\%).

In terms of DALY ${ }^{1}$, mental disorders rank highest compared to the morbidity burden resulting from all other causes, but at the same time the treatment gap is enormous. The economic estimates were also revised accordingly, resulting in total costs of $€ 798$ billion (2010 prices) of which $40 \%$ are indirect costs, $37 \%$ direct medical and $23 \%$ non-direct medical costs [8][9]. 
There are also several national cost-of-illness studies available. For instance, the total costs of mental disorders in France were estimated at $€ 109$ billion in 2007 [10]. By using a top down approach, direct health care costs, direct non-medical costs, indirect costs and intangible costs were derived. Within direct health care costs, public psychiatric hospitals had the highest costs of $€ 6.4$ billion while the costs for out-patient care accounted for $€ 4.7$ billion. Direct non-medical costs were estimated at $€ 6.3$ billion, of which $€ 3$ billion were for institutions in the health and social care sector, $€ 2$ billion for allowances, and interestingly also of $€ 1.3$ billion for informal care. In terms of indirect costs, the costs of income compensation accounted for $€ 4.4$ billion and the costs of productivity losses for $€ 20$ billion. Surprisingly, intangible costs, i.e. loss of quality of life, were also assessed, resulting in a loss of 2.2 million QALY ${ }^{2}$ and costs of $€ 65.08$ billion.

In a study set out to determine the economic burden of mental disorders in Sweden, annual costs were estimated at $€ 9.4$ billion (2001 values) of which $€ 1.9$ billion were direct costs and $€ 7.5$ billion were indirect costs [11]. From a methodological point of view, these findings are based on prevalence rates of mental disorders, the cost-of-illness approach and a top down perspective.

\section{Generalized anxiety disorder}

The symptoms of generalized anxiety disorder (GAD) comprise tension, worrying and anxiety symptoms [12] $]^{3}$. Generalized anxiety disorder is considered to be associated with high individual burden as a consequence of its chronic course [13]. Wittchen [14] found that GAD is the most frequent anxiety disorder treated in primary care settings. In a systematic review, the economic and human burden of this disorder was assessed with the focus on North America and a selection of European countries in the period from 1987 to 2010 [15]. A total of ninety studies met these inclusion criteria. Despite differing diagnostic criteria used in the epidemiologic studies that were analyzed, the effects on productivity, health related quality of life and psychological functioning can be distinguished which lead to burdensome impairments in the sphere of individual functioning and well-being, condensed in high medical costs and the use of health care services. As a further outcome, the health related quality of life impacts are similar to panic disorder or depression. Life time prevalence rates differ among the studies owing to changing diagnostic patterns, but are in the range of $3 \%$ to $6 \%$. Estimating

\footnotetext{
1 DALY ("disability adjusted life year") is a health economic measure, expressing a burden of a disease in the number of years lost due to an illness or disability. One DALY equals one year of life in total health. DALYs are calculated as the sum of years of life lost and the years lost to disability.

2 QALY ("quality adjusted life year") measures the quantity and quality of life generated by a health intervention and weights time in different health states.

3 Unless specified differently, all diagnostic criteria used in this chapter refer to ICD-10 guidelines edited by Dilling et al. (8th revision, 2011)
} 
direct and indirect costs associated with generalized anxiety disorder is difficult, but the results suggest that the median medical costs for patients suffering from this disorder are significantly higher than for patients without this disorder. Another aspect under analysis was the treatment rate, limiting the scope of the review only to pharmacologic interventions. Surprisingly, generalized anxiety disorder is still an under-diagnosed and highly untreated disorder, notwithstanding the significant burden of the disease.

Hoffmann et al. [16] analyzed 24 studies and identified the human burden, quantitatively expressed in terms of quality of life and role functioning, as well as the economic burden, defined as health care utilization costs and productivity losses. Only studies based on DSMIII-R, DSM-IV or ICD-10 criteria covering the period from 1990 to 2005 were included, using MEDLINE and PsychLIT database. As a result, the economic consequences and individual burden associated with GAD are considerable and comparable with other mental disorders (i.e. other anxiety disorders, somatoform disorders) as well as somatic problems.

Based on patient survey data from Germany, Spain, Italy, France and the United Kingdom, the economic and human burden of GAD were identified [17]. Cost analyses, as well as bivariate and multivariate approaches, showed that patients suffering from GAD have more co-morbidities, resource use and work impairments and a less health-related quality of life than control groups without GAD.

The costs of anxiety disorders in Europe were assessed by utilizing the mental health supplement of the German National Health Interview and Examination Survey, a community sample ( $n=4181$, age=18-65) conducted in 1998/1999 [18]. The mean costs were derived as excess costs (i.e. compared with individuals without an anxiety disorder) per patient. In the case of GAD, the direct cost per patient amounts to $€ 1,230$ and the indirect costs to $€ 399$, resulting in a total of $€ 1,629$ (2004 prices).

\section{Affective disorders}

Affective or mood disorders are characterized by a fundamental change in mood and are accompanied by a change in activity levels. Bipolar disorders are marked by a switch of mood, at least two episodes in which the patient's mood and activity levels are significantly disturbed, consisting of an elevation of mood and increased activity (mania or hypomania) and of a lowering of mood and decreased activity (depression). In between the episodes complete remission can be expected. It is interesting to note that more studies on the economics of unipolar depressions are available than on bipolar type I and II disorders [19]. The co-morbidity of depressive disorders with other mental disorders, as well as somatic illnesses, is high, but studies have neglected the (lifetime) incidence of these major disabling conditions [20]. Depression or depressive episodes can vary from being mild, moderate, or severe depending upon the number and severity of the symptoms. Typical symptoms are a lowering of mood, decrease in activity and reduced self confidence accompanied by somatic symptoms such as disturbed sleep and weight loss [12]. 


\subsection{Depression}

In 2005, the costs of depression in Sweden from a prevalence based top down perspective amounted to $€ 3.5$ billion, with indirect costs of $€ 3$ billion and direct costs of $€ 500$ million [21]. This study also estimated the intangible costs of suffering based on the QALY losses of patients undergoing treatment ( $€ 4.1$ billion) and for those patients who do not receive any treatment (€ 6.1 billion).

Another study based on a similar methodological approach estimated the total costs for depression at $£ 9$ billion (2000 values) in England, where direct costs constitute only a minor share of $£ 370$ million [22]. As part of the "Epidemiology of Mental Disorders (ESEMeD) project", a prevalence based bottom up approach was employed by Friemel et al. to assess the direct costs of depression in Germany, which amounted to $€ 1.6$ billion in 2002 [23].

Berto et al [24] analyzed the costs of depression based on a review of seven studies. According to their findings, depression imposes a remarkable burden on society, which led to direct and indirect costs of $\$ 43.7$ billion in the US as well as of $£ 417$ million in the UK in 1990. It is interesting that 5 out of 7 studies indicated that in terms of direct costs hospitalization incurs the most costs while medication accounts for only a minor share. The economic burden is high owing to the chronicity, early onset and high prevalence of depression to be found not only among the working population but also in general [25].

\subsection{Bipolar disorders}

Recently, bipolar disorders in the EU25 and Switzerland, Norway and Island were analyzed. Only studies published after 1980 that were based on DSM-III-R, DSM-IV or ICD-10 criteria were considered. Epidemiologic samples in the clinical population or community, as well as studies using structured or standardized diagnostic interviews, were included in the study [26]. Thus, 14 studies carried out in 10 countries revealed that the 12-month prevalence of these disorders lies within the range of $0.5-1.1 \%$. Another interesting result was that there are only few studies available concerned with the disability and treatment of bipolar disorders. In comparison with other mood disorders, substance use disorders or anxiety disorders, people suffering from bipolar disorders are characterized by a higher level of disability with regard to severity and duration. In addition these patients also have higher productivity losses expressed in absenteeism. The data on treatment and the utilization of health services are scarce. This might be owing to the fact that bipolar disorders are rather rare. However, comorbidity with other mental disorders, as well as somatic diseases, is high.

The annual societal costs of bipolar disorders in the UK were assessed with the help of health care and statistical databases, and amounted to a total of $£ 2.06$ billion in 2001/2002 [27]. This estimate includes $£ 199$ million direct health care costs, $£ 86$ million direct non-health care costs and $£ 1.77$ billion indirect costs. In a comparable way, Runge et al analyzed German health insurance data and estimated the annual societal costs of $€ 5.8$ billion (2002 prices) [28]. Indirect costs account for $€ 5.7$ billion, direct costs for $€ 138$ million. 
In both studies, bipolar disorders implied a substantial economic burden and the largest share of direct costs was for inpatient treatment (35\% in UK; 60\% in Germany). In addition, indirect costs exceeded direct costs several times over.

A recent review analyzed systematically 22 cost-of-illness studies [29]. Only studies published since 2000 and meeting 20 elaborated quality criteria were selected with a focus on the cost of illness data for bipolar disorders. Despite the fact that all of the studies reviewed assessed the major costs associated with bipolar disorders, the comparison of estimates was impeded by the plurality of study outcomes on the national and international levels.

Fajutrao et al (2009) [30] carried out a systematic literature review using Medline, Embase and Biosis as well as health technology assessments and treatment guidelines. The analysis of 25 studies dealing with epidemiology, costs and patient related issues (e.g. employment, disability) of bipolar disorders in Europe (i.e. United Kingdom, Sweden, Spain, Germany, France and Italy) emphasises the underestimation of this long-term disorder and high economic burden both in terms of direct and indirect costs.

\section{Schizophrenia}

Schizophrenia is a chronic and highly disabling mental disorder characterized by thought disorders, hallucinations and delusions (positive symptoms) as well as apathy, incongruity of emotional responses and paucity of speech (negative symptoms) [31]. There is a considerable amount of literature in which the burden of schizophrenia, together with the interrelated dimensions of cognitive functioning, quality of life, stigma and also the burden for caregivers is discussed [32] [33] [34].

There have been some controversial discussions on mortality and associated risk factors [35] [36]. Life expectancy in the light of cardiovascular diseases [37][38] was subject to studies as well as risk factors and suicide rates [39]. To sum up, the causes of mortality in patients with schizophrenia are unnatural deaths, cardiovascular diseases, respiratory diseases and cancer. However, it has been recognized only recently that natural causes are very often the reason for mortality [40].

The costs associated with this disease are high and wide ranging because of the burden on the patients per se, relatives who care for them and society at large [41]. Some analysts [42] have attempted to draw fine distinctions between direct medical and direct non-medical costs, the latter consist of informal care costs. In their prevalence based study on the social costs of schizophrenia in Spain a total of $€ 1.97$ billion (2002 prices) was calculated, of which $53 \%$ were direct medical costs (inpatient and outpatient care, medication) accounting for $2.7 \%$ of the total public health expenditure.

A notable example of a prevalence based bottom up study provides a differentiated consideration of the costs in 2004/2005 in England [43]: taking into account various populations (private households, residential institutions, prisons, the homeless) the total costs of schizo- 
phrenia were $£ 6.7$ billion. Only $£ 2$ billion were spent for direct treatment and care costs, but $£ 4.7$ billion were indirect costs as summarized in the following table.

\begin{tabular}{ll}
\hline Lost productivity of patients & 3400 \\
Private expenditures and informal care & 615 \\
Benefit payments & 570 \\
Lost productivity of carers & 32 \\
Administration of benefit payments & 14 \\
Criminal justice system & 1 \\
\hline Source: table based on [43] & \\
\hline
\end{tabular}

Table 1. Indirect costs of Schizophrenia in England in 2004 ( $£$ millions)

\section{Alcohol}

Similarly, studies on alcohol abuse vary considerably in estimating the burden on individuals and society. In the past decade, alcohol and other substance use disorders have gained attention as one of the major public health problems. [44]. Neither prevalence nor costs attributable to addiction are easy to quantify [45]. A specific problem is causality, whether health issues are a consequence of alcohol or some other cause [46]. Whatever the case, comorbidity with other mental disorders [47] is frequent and there are also causal links to physical problems [48]. Another problem is that the diagnosis and differentiation in the forms of alcohol abuse to be found in studies on the subject range from acute intoxication, harmful use, dependence and withdrawal state [12]. Alongside with increased morbidity and comorbidity, alcohol is associated with violence [49] and crime [50]. With regard to the prevalence of alcohol abuse disorders, the median 12-month prevalence of alcohol dependence alone in the EU 25 and Norway is $6.1 \%$ for the male and $1.1 \%$ for the female populations, respectively [51].

Recent evidence suggests that alcohol dependence is even more expensive than alcohol abuse, if health costs per patient are considered [52]. In 2002, a prevalence based Swedish study estimated the societal costs resulting from alcohol consumption at SEK 29.4 billion or $1.3 \%$ of GDP [53]. By far the largest share of the total costs were the indirect costs accounting for SEK 18.4 billion. A German study calculated a value of $1.16 \%$ of GDP in 2002, based on the concept of attributable fractions and prevalence [54]. This result corresponds to the total costs of $€ 24.4$ billion, including the direct costs of $€ 8.44$ billion and indirect costs of $€ 15.96$ billion. In both studies no specification of alcohol abuse in terms of a mental disorder according to diagnostic manuals is available and the research focus is on alcohol consumption in general. Thus, the potential positive effects (i.e. protective health effects) were discussed too, but presented separately. 


\section{Dementia and mental health of the elderly}

As a consequence of demographic developments the prevalence of mental disorders in old age is assumed to increase [55]. But, so far, little is known about the health care situation of the elderly with mental disorders apart from those with those with dementia and depression [56]. The various forms of dementia are a major health problem for the older generation in Europe. According to ICD-10, various types can be distinguished. Alzheimer's disease is the most frequent form of dementia, but also vascular dementia caused by a stroke (cerebrovascular accident CVA) is very common. With regard to the prevalence of Alzheimer in those who are over 65 years of age, the rate ranges between $5.9 \%$ and $9.4 \%$, depending on age, sex and severity [57]. A recent review of 15 cost-of-illness studies based on patient-level data, showed that the median annual costs amounted to $€ 28,000$ (2005 values) which were solely for the care of patients with Alzheimer's disease [58] f. From a societal perspective, the annual baseline costs of dementia in Ireland were estimated at over $€ 1.69$ billion in 2010 [59]. A combination of bottom up and top down approach was adopted. Informal care accounts for $48 \%$ of the total costs, residential long-stay care for $43 \%$, while for formal social and health care it is for $9 \%$. For Hungary, the costs of dementia were assessed by a cross-sectional non-population-based study [60], resulting in total annual costs for the demented population of $€ 846.8$ million for 2010 . The highest proportion of these costs is attributable to direct costs $(55 \%)$, followed by informal care $(36 \%)$ and indirect costs $(9 \%)$.

The costs for dementia for the EU-27 amounted to $€ 160$ billion in 2008, with a range from $€$ 111 to $€ 168$ billion [61], based on a cost model developed upon 14 cost-of-illness studies reviewed.

\section{Child and adolescent mental health}

The prevalence of child and adolescent mental disorders has increased [62]. The most common mental disorders in childhood and adolescence are hyperkinetic disorders (ICD-10) or attention-deficit hyperactivity disorders (ADHD, according to DSM-IV) [63]. The predominant symptoms are ill-regulated, disorganized and excessive activity and lack of persistence in activities requiring cognitive involvement. The children who are affected tend to be impulsive, socially isolated and lack self confidence. The cognitive functions are also frequently impaired. An early onset (usually during the first five years of a child's life) and overlapping difficulties in various aspects of life (education, establishing social ties) continuing until adulthood are distinctive. Symptoms of conduct disorders include a persistent pattern of aggressive, dissocial or defiant conduct. A characteristic of this disorder is also the inability to conform with the social expectations appropriate to the child's age. Severe other mental disorders may also exist (e.g. personality disorders). Autism is assigned to the group of pervasive developmental disorders and is defined by reciprocal social interaction, abnormalities in patterns of communication, as well as stereotyped behaviour and activities in all areas of the individual's functioning. [12] 
The economic burden of mental disorders with onset usually occurring in childhood and adolescence is enormous. The vast majority of literature on ADHD is based on US data, but few European studies are available. From the results of the analysis of German statistical data, medical costs associated with hyperkinetic disorders alone amounted to $€ 142$ million in 2002, which is a first estimate and a rather conservative one [64]. A comparison of children with and without ADHD in Belgium (Flanders) showed that the families and patients are faced with a high (psycho)social and economic burden [65]: based on a questionnaire sent to a non-random sample, the private costs borne by parents amounted to $€ 533$ per year for the parents, and the public costs came to $€ 779$ in 2002 . These costs are six and twice as high, respectively, than for children who do not suffer from ADHD. The results of a review of European evidence on ADHD were applied to the case of the Netherlands [66], where the average total costs ranged between $€ 1,041$ and $€ 1,529$ million, depending on the application of high or low level scenarios (2012 prices). The lion's share of the costs at $€ 648$ million was allocated to education including additional school lessons and costs for the services of educational psychologists and other health care professionals. The productivity losses of the members of the family accounted for $€ 143-€ 339$ million, health care costs for the members of the family amount to $€ 161$ million. Patient health care costs ranged from $€ 84-€ 377$ million and social care costs were estimated at $€ 4.3$ million.

Conduct disorders are common too, but prevalence rates vary owing to diagnostic difficulties and to which subjects and/or populations are included in the study [67]. The first German study on the costs of conduct disorders was based on a retrospective analysis of data from a statutory health insurance institution for the period 2006-2009 and resulted in annual mean expenditures of $€ 2,632$, which are 3.8 times higher than those for a matched control group [68]. From a multicentre controlled trial of groups taking over the role of a parent to deal with antisocial behavior in childhood a sample was drawn to estimate the costs of anti-social behaviour in the UK [69]: the annual mean costs of health, voluntary and educational services were estimated to be a $£ 1,277$, the costs for members of the family, resulting from absence from work, additional repair as well as household tasks were $£ 4,637$ (2002/2003 prices).

The spectrum of autism disorders was analyzed in two British studies: while Knapp et al. estimated the annual costs, based on prevalence and different data sources for children of different age groups to be $£ 2.7$ billion and for adults to be $£ 25$ billion separately (2005/2006 prices) [70], Barett et al undertook a randomized controlled trial of a communication intervention which focussed on autism in children under 5 years of age and used the prevalence rates of the former study. Thus, the estimated service costs for this subgroup amounted to $£$ 109 million and the wider societal costs at $£ 130$ million per annum [71].

Based on the British Child and Adolescent Mental Health Surveys, a study on the economic burden of children aged 5-15 with a conduct, hyperactivity or emotional disorder (ICD-10) estimated the national costs for the health, education and social care services at $£ 1.47$ billion in 2008, the largest share of which was for the education services [72]. 


\section{The Austrian case}

The Austrian welfare system can best be described as corporatist and conservative because of the dominance of social insurance and the strong linkage to paid employment [73]. Health, as a dimension of social policy, incurs the second largest proportion of expenditure and is primarily funded by health insurance contributions [74]. In 2012, the total health care expenditures (public and private) amount to $€ 34,067$ million, which corresponds to $11.1 \%$ of GDP [75]. A total of 22 social security institutions and the Main Association of Austrian Social Security Institutions (i.e. Hauptverband der Sozialversicherungsträger) organize health, accident and pension insurance [76]. There are no specific benefit payments in the case of a mental illness, but the general benefits and other support (e.g. subsidies for education, reintegration programmes, supported employment) are also of high importance for the mentally ill [77].

\subsection{Mental health care}

In Austria, there is no national mental health care system, but there are reforms and initiatives that are aimed at achieving international targets, such as deinstitutionalization, decentralization of services and equity of mental and somatic illnesses [78]. Because of Austria's federal structure the efforts made by the nine federal provinces in terms of data collection and availability at the level of provinces differ. Thus, the most recent psychiatry report including information on inpatient and outpatient care deals only with the situation in the province of Vorarlberg [79]. Within the last 5 years, besides Vorarlberg, only Styria [80] published up-todate information on the provision and utilization of services regularly. The last national psychiatry report dates back to 2004 [81], but the Austrian Health Care Structure Plan, as the key planning instrument in the health care sector, includes psychiatric care on all levels of provision [82].

The Main Association of Austrian Social Security Institutions also published a national strategy on mental health [83]. Within this strategy, 25 targets are established that can prevent illness, improve treatment and reduce disability associated with mental disorders. Data on the history of suicide rates and spatial, socio-economic as well as gender patterns is also available [84][85] [86]. In addition, a national programme on suicide prevention was adopted recently [87]. A detailed report on alcohol consumption, alcohol related inpatient health service utilization, morbidity and mortality is available for Austria [88].

The federal organisation of health care also necessitates different financing structures of mental health care services [89]. The system of financing psycho-social services is complex. For instance, the model for funding psychotherapy can illustrate the juxtaposition of different possibilities. Psychotherapy can be financed privately, which guarantees the freedom of choice of an adequate psychotherapist. However, based on the principle of benefits in kind, health insurance covers the costs for psychotherapy in total only under specific conditions, but these are limited and waiting lists are long. Finally, a mixed form is the subsidy or co-payment through health insurance [90]. 
Particularly children and adolescents are a vulnerable but neglected group within the care system [91]. Insufficiencies in the treatment structures are evident in the inpatient and outpatient sectors as well as in the sector of registered doctors, where the respective WHO indicators are not met [92]. Inpatient treatment is predominant, while psychotherapy and specialized ambulatory care practically do not exist without additional costs for those caring for the patient [93].

\subsection{The costs of mental disorders in Austria}

The costs of mental disorders are huge as the previous sections on selected disorders have shown. Although there have been a few recent studies on this subject, Austrian data is scarce. Based on statutory health insurance data, about $9 \%$ of the Austrian population or 900,000 (insured) Austrians made use of the health services to receive treatment for mental illness in 2009 [94].The associated costs in terms of medication, inpatient treatment, psychotherapy, physician services, psychiatric and psychological services, as well as sick pay were estimated at $€ 790-850$ million. This estimate excludes rehabilitation costs as well as disability pensions, where it is important to note that mental disorders are the most common cause for new disability pension claims.

Wancata et al. [95] calculated the costs of 12 mental and neuropsychiatric disorders of the brain as part of the first European cost study [6] [7]. Thus, direct medical costs and direct non-medical costs were derived. Indirect costs were estimated based on the human capital approach. Anxiety disorders, affective disorders (bipolar disorders and depression), addiction (alcohol and illegal drugs), migraine, psychotic disorders, dementia, epilepsy, Parkinson's disease, stroke (cerebrovascular accident), multiple sclerosis, brain tumours and brain trauma were analyzed. With regard to the 12 month prevalence, in 2004 anxiety disorders were the most prevalent disorders (847,622 cases), followed by affective disorders (479,091 cases) and addiction (194,795 cases). In terms of costs per case and per mental disorder, the estimates are based on data from the review on the European level: dementia caused the highest costs at $€$ 13,635 followed by psychotic disorders at $€ 9,487$ and affective disorders at $€ 5,138$ (2004 prices). Taking the Austrian population as a whole, the costs for these 12 disorders amounted to $€ 8.8$ billion, whereas $47 \%$ are indirect costs (productivity loss), $37 \%$ are direct non-medical costs and $17 \%$ are direct medical costs. The authors emphasize that the results must be taken with caution, because the values were extrapolated from averaged and adjusted data taken from other studies owing to the lack of epidemiologic and cost data, respectively. Bearing these limitations in mind, the estimates presented should serve only as a first classification (Table 2).

Costs associated with schizophrenia were analyzed as part of a comprehensive report on this mental disorder in Austria [96]. The most important finding was that there are major gaps in the knowledge and data on this subject. In a short international survey of the studies available, the differences given in the direct and indirect cost estimates on account of the specific characteristics of the underlying health systems and thus of the treatment and care programs, are significant. With regard to the Austrian case, a search in Medline database brought to light one article which dealt with the burden that not only those with this disorder also their families 


\begin{tabular}{lllll}
\hline Mental Disorder & Direct costs & $\begin{array}{l}\text { Direct non-health } \\
\text { care costs }\end{array}$ & Indirect costs & Total costs $^{1}$ \\
\hline Affective disorders & 617 & ---- & 1845 & 2462 \\
Anxiety disorders & 427 & ---- & 428 & 856 \\
Dementia & 262 & 833 & ---- & 1094 \\
Addiction & 260 & 40 & 1043 & 1444 \\
Psychoses & 1095 & 204 & ---- & 1299 \\
\hline
\end{tabular}

${ }^{1}$ These figures are estimations only. Therefore the sum may not be exact as it is either rounded up or down. Source: estimates extracted from [93]

Table 2. Total costs of selected mental disorders in 2004 (€, millions)

have to bear, respectively. In Austria only few health care service data are recorded directly related to a diagnosis, which is a prerequisite for an appropriate application of cost-of-illness studies. For instance, inpatient care is filed related to the diagnosis, but sick-leaves and prescriptions are not documented according to ICD-10 criteria. Thus, a collection of diagnosisbased data for all health and care services throughout Austria is not feasible, which makes it difficult to obtain statements on the current size and burden of schizophrenia. Despite these limitations, the data from the Main Association of Austrian Social Security Institutions, from the Upper Austrian regional health insurance fund (i.e. Oberösterreichische Gebietskrankenkasse), the Austrian Federal Pension Fund and Statistics Austria could be used. As a result, the number of hospital inpatient stays is steadily declining. Not only the number of patients taking sick-leave because of a mental illness, but also the duration of this leave has increased in Austria, but there is no detailed analysis as there is a lack of data. In 2006, the Upper Austrian regional health insurance fund reported 14,010 sick-leave days incurring costs of $€ 198,802$ for the insured persons with schizophrenia. This comparatively low number might be due to the fact that patients suffering from schizophrenia are likely to prematurely leave the employment market or have difficulties in accessing the employment market. Focusing on pension benefits, it can be said that schizophrenia is one of the most frequent reasons that claims are made. It is an interesting fact that more than $90 \%$ of the pension claims made because of schizophrenia are approved, while the refusal rate for claims based on other mental disorders is approx. $39 \%$. The average age of patients with schizophrenia is 40 when they apply for a pension and are thus more than 10 years younger than claimants with other disorders.

A recent cost benefit analysis suggests that alcohol abuse disorders incure high costs for Austria's public health system. As a result, the costs outweigh the "benefits" (i.e. tax revenues) at the rate of $0.25 \%$ of GDP (i.e. $€ 737.9$ million, 2011 prices) [97].

At the European level, Austria was also part of the updated review on costs of disorders of the brain in the EU-27 countries [8]. Estimates for selected mental disorders in 2010 are shown below (Table 3 ). Taking into account that these estimates are highly aggregated and partly based on extrapolation, the results may be classified as first ranges as it is given that primary data in Austria is insufficient. 


\begin{tabular}{ll}
\hline Mental disorder & Total costs \\
\hline Addiction & 1282 \\
\hline Anxiety disorders & 1568 \\
\hline Child/ Adolescent mental disorders & 425 \\
\hline Dementia & 1451 \\
\hline Mood disorders & 2253 \\
\hline Psychotic disorders & 1961 \\
\hline
\end{tabular}

Source: extracted from [8]

Table 3. Estimates of selected mental disorders in Austria (€PPP million, 2010)

\section{Discussion}

One may suppose that the blind spots in mental health care research are negligible.. But in view of the limitations in methodologies adopted for the estimates, both with regard to the prevalence of mental disorder and the costs they incur, the conclusiveness of the results may not be given (as indicated by most authors).

When it comes to the economic evaluation of mental disorders, suicidal behaviour and suicide give rise to controversy. On the one hand, it can be argued that suicide must be included in cost analyses in terms of lost productivity owing to premature mortality. On the other hand, suicide attempts result in medical costs. Some authors even discuss the potential savings if a suicide is carried out as treatment is no longer required and pension benefits and care costs are reduced [98]. However, suicide has been excluded or described only qualitatively in most of the recent studies.

Another key aspect is co-morbidity-whether with other mental disorders or somatic illnesseswhich can be considered only insufficiently in the studies and approaches available. Multiple co-morbidities are common in patients suffering from mental disorders. Thus, the burden might have been underestimated. A rather sensitive matter is the consideration of criminal justice costs. Establishing a cause-effect link is difficult, but it is a fact that stigmatization and discrimination are interrelated. Stigmatization may also be a reason why patients do not seek any treatment at all. It is assumed, in most of the studies, that a high number of persons with mental disorders remain untreated. This treatment gap also infers that current cost estimates might be too low.

The cost estimates presented show that the burden, both for society and individuals, is tremendous. However, the estimates can be classified as conservative. All of the studies indicate that the indirect costs are an even larger burden than the direct costs incurred by making use of the health services. There are, however, also studies in which only the direct costs for health care systems are estimated. Only one study estimated the intangible costs in monetary terms [21]. Throughout the studies, the costs and cost categories are not applied in a consistent way, since there are no international standards. The comparison of cost estimates, 
especially in the case of studies utilizing the top-down approach, may be hindered by the presence of heterogeneous public health systems as well. Thus, the different systems of data collection, funding of health and social services, categorizing and grouping of medical and psycho-social services may account for different study outcomes. However, the findings of the cost-of-illness studies are summarized below (Table 4).

\begin{tabular}{|c|c|c|c|c|c|c|c|c|}
\hline $\begin{array}{l}\text { Mental } \\
\text { Disorder }\end{array}$ & $\begin{array}{l}\text { Reference } \\
\text { (year of costs) }\end{array}$ & $\begin{array}{l}\text { Country/ } \\
\text { currency }\end{array}$ & Approach & $\begin{array}{l}\text { Direct } \\
\text { costs }\end{array}$ & $\begin{array}{c}\text { Direct } \\
\text { non } \\
\text { health } \\
\text { care costs }\end{array}$ & $\begin{array}{c}\text { Indirect } \\
\text { Costs }\end{array}$ & $\begin{array}{l}\text { Total } \\
\text { costs }\end{array}$ & $\begin{array}{c}\% \text { of total public } \\
\text { health care } \\
\text { expenditure }^{1}\end{array}$ \\
\hline \multirow[t]{3}{*}{ Depression } & [21] (2005) & $\begin{array}{l}\text { Sweden } \\
€\end{array}$ & $\begin{array}{l}\text { Prevalence } \\
\text { based, } \\
\text { top down }\end{array}$ & 500 & & 3000 & 3500 & 2.4 \\
\hline & [22] (2000) & $\begin{array}{l}\text { England } \\
£\end{array}$ & $\begin{array}{l}\text { Prevalence } \\
\text { based, } \\
\text { top down }\end{array}$ & 370 & & 8630 & 9000 & n.a. \\
\hline & [23] (2002) & $\begin{array}{l}\text { Germany } \\
€\end{array}$ & $\begin{array}{l}\text { Prevalence } \\
\text { based, bottom } \\
\text { up }\end{array}$ & 1600 & & & 1600 & 0.9 \\
\hline \multirow[t]{2}{*}{$\begin{array}{l}\text { Bipolar } \\
\text { disorders }\end{array}$} & [27] (2001) & $\begin{array}{l}\text { UK } \\
£\end{array}$ & $\begin{array}{l}\text { Health care } \\
\text { data, statistics }\end{array}$ & 199 & 86 & 1770 & 2060 & n.a. \\
\hline & [28] (2002) & $\begin{array}{l}\text { Germany } \\
€\end{array}$ & $\begin{array}{l}\text { Health } \\
\text { insurance } \\
\text { data, statistics }\end{array}$ & 138 & & 5700 & 5800 & 0.08 \\
\hline \multirow[t]{2}{*}{$\begin{array}{l}\text { Schizo- } \\
\text { phrenia }\end{array}$} & [42] (2002) & $\begin{array}{l}\text { Spain } \\
€\end{array}$ & $\begin{array}{l}\text { Prevalence } \\
\text { based }\end{array}$ & 1044 & 926 & & 1970 & 2.4 \\
\hline & [43] (2004) & $\begin{array}{l}\text { England } \\
£\end{array}$ & $\begin{array}{l}\text { Prevalence } \\
\text { based, bottom } \\
\text { up }\end{array}$ & 2000 & & 4700 & 6700 & n.a. \\
\hline \multirow[t]{2}{*}{ Alcohol } & [53] (2002) & $\begin{array}{l}\text { Sweden } \\
\text { SEK }\end{array}$ & $\begin{array}{l}\text { Prevalence } \\
\text { based }\end{array}$ & 10987 & & 18394 & 29400 & 5.8 \\
\hline & [54] (2002) & $\begin{array}{l}\text { Germany } \\
€\end{array}$ & $\begin{array}{l}\text { Prevalence } \\
\text { based, } \\
\text { attributable } \\
\text { fractions }\end{array}$ & 7064 & 1377 & 15958 & 24398 & 3.9 \\
\hline
\end{tabular}

${ }^{1}$ own calculation based on EUROSTAT [99]. Results include direct costs only. Data of the United Kingdom is not available in Eurostat's

System of National Health Accounts. In the case of Sweden and Germany 2003 values were adopted owing to comparability.

Table 4. Summary of original cost-of-illness studies (millions)

To sum up the cost of illness part of this chapter, the following table presents the total cost estimates converted into Euros (2013 values). As already indicated above, a comparison of 
single cost estimates is hindered by several factors. However, the scale of the economic burden of selected mental disorders is apparent.

\begin{tabular}{|c|c|c|c|c|}
\hline Mental Disorder & $\begin{array}{c}\text { Reference } \\
\text { (year of costs) }\end{array}$ & Country & $\begin{array}{l}\text { Total costs } \\
\text { (millions) }\end{array}$ & Per capita costs ${ }^{1}$ \\
\hline \multirow[t]{3}{*}{ Depression } & [21] (2005) & Sweden & 3948 & 413 \\
\hline & [22] (2000) & England & 15116 & n.a. \\
\hline & [23] (2002) & Germany & *1934 & 24 \\
\hline \multirow[t]{2}{*}{ Bipolar disorders } & [27] (2001) & UK & 3434 & 54 \\
\hline & [28] (2002) & Germany & 7012 & 85 \\
\hline \multirow[t]{2}{*}{ Schizophrenia } & [42] (2002) & Spain & *2 689 & 58 \\
\hline & [43] (2004) & England & 10733 & n.a. \\
\hline \multirow[t]{2}{*}{ Alcohol } & [53] (2002) & Sweden & 3816 & 399 \\
\hline & [54] (2002) & Germany & 29496 & 360 \\
\hline \multicolumn{5}{|l|}{ only direct costs } \\
\hline
\end{tabular}

Table 5. Summary of cost-of-illness studies presented in 2013 Euros

The relevance of mental health in specific population groups has been outlined. Dementias in the elderly population are a challenge to the health and social care systems, as life expectancy and prevalence have increased. The role of informal care is striking, raising the question how relatives can be supported faced with the burden of long term care and how care should be organised and financed respectively in times of limited resources.

With regard to the mental health of children and adolescents, the studies that have been discussed emphasize not only the burden on the patients, but also on the members of their families and carers.

A high share of the costs related to a child's mental disorder is borne by the parents. The health care and social care sector are affected in terms of costs, but in particular the educational services sector is stretched. Associated problems, such as poor education in adolescence, imply a worse socio-economic status and related adverse effects in adulthood [101].

Finally, the case of Austria illustrates that national cost data and epidemiology measures are scarce and scattered, impeding general statements on the current state of mental health of the population. On the one hand, cost data of several health insurance institutions indicate the burden of mental disorders in terms of the utilization of medical resources, health services as well as the impact on the number, duration and costs of taking sick-leave. Despite data insufficiencies, these cost estimates provide an initial overview of the importance of mental disorders at the societal level. On the other hand, the cost of illness information based solely 
on national primary data is currently not available, and thus prevents a more profound analysis of the role of specific mental disorders in the social and health care system.

\section{Conclusion}

Collectively, the studies mentioned in this review outline the critical role of mental health in European public health systems in terms of the provision of proper treatment as well as prevention programmes. Analyses of the single cost-of-illness studies have shown that estimates are often based on extrapolated data. Assumptions with regard to the epidemiology of a specific mental disorder affect study outcomes inevitably. The need for research and concerted action in mental health seems to be apparent. Appropriate data and health economic studies would lead to more informed decisions when it comes to the allocation of scarce resources in the health care system.

\section{Author details}

Denise $\mathrm{Zak}^{*}$

Address all correspondence to: denise.zak@tuwien.ac.at

Center of Public Finance and Infrastructure Policy, Department of Spatial Planning, Vienna University of Technology, Austria

\section{References}

[1] Frank, R.G. (2011). Economics and mental health: an international perspective. In: Glied S (Hrsg.). The Oxford handbook of health economics. Oxford Univ. Press, Oxford, 232-256.

[2] Büscher, G., Gerber, A. (2010). Gesundheitsökonomische Evaluationen als Ansatz zur Steurung der Ausgaben im Gesundheitswesen. In: Lauterbach, K. W., Lüngen, M., Schrappe, M. (Ed.). Gesundheitsökonomie, Management und Evidence based medicine: Handbuch für Praxis, Politik und Studium; mit 71 Tabellen. Schattauer Verlag, Stuttgart, 63-81.

[3] König, H. H., Friemel, S. (2006). Gesundheitsökonomie psychischer Krankheiten. Bundesgesundheitsblatt-Gesundheitsforschung-Gesundheitsschutz, 49(1), 46-56.

[4] Salize, H.J., Kilian, R. (2010). Gesundheitsökonomie in der Psychiatrie. Kohlhammer, Stuttgart 
[5] Andlin-Sobocki, P., Jönsson, B., Wittchen, H. U., Olesen, J. (2005). Cost of disorders of the brain in Europe. European Journal of Neurology, 12(s1), 1-27.

[6] Wittchen, H. U., Jacobi, F. (2005). Size and burden of mental disorders in Europe-a critical review and appraisal of 27 studies. European neuropsychopharmacology, 15(4), 357-376.

[7] Wittchen, H. U., Jacobi, F., Rehm, J., Gustavsson, A., Svensson, M., Jönsson, B., Olesen, J., Allgulander, C., Maercker, A., van Os, J., Preisig, M., Salvador-Carulla, L., Simon, R., Steinhausen, H. C. (2011). The size and burden of mental disorders and other disorders of the brain in Europe 2010. European Neuropsychopharmacology, 21(9), 655-679.

[8] Gustavsson, A., Svensson, M., Jacobi, F., Allgulander, C., Alonso, J., Beghi, E., et al (2011). Cost of disorders of the brain in Europe 2010. European Neuropsychopharmacology, 21(10), 718-779.

[9] Olesen, J., Gustavsson, A., Svensson, M., Wittchen, H. U., Jönsson, B. (2012). The economic cost of brain disorders in Europe. European Journal of Neurology, 19(1), 155-162.

[10] Chevreul, K., Prigent, A., Bourmaud, A., Leboyer, M., Durand-Zaleski, I. (2012). The cost of mental disorders in France. European Neuropsychopharmacology, 28(8), 879-886.

[11] Tiainen, A., \&Rehnberg, C. (2010). The economic burden of psychiatric disorders in Sweden. International journal of social psychiatry, 56(5), 515-526.

[12] Dilling, H., Mombour, W., Schmidt, M.H. (2011). International Klassifikation psychischer Störungen. ICD-10 Kapitel V (F) Klinisch-Diagnostische Leitlinien, 8.th ed., Verlag Hans Huber, Bern.

[13] Allgulander, C. (2006). Generalized anxiety disorder: What are we missing? European Neuropsychopharmacology, 16, Supplement 2, 101-108.

[14] Wittchen, H. U. (2002). Generalized anxiety disorder: prevalence, burden, and cost to society. Depression and anxiety, 16(4), 162-171.

[15] Revicki, D. A., Travers, K., Wyrwich, K. W., Svedsäter, H., Locklear, J., Mattera, M. S., Sheehan, D.V., Montgomery, S. (2012). Humanistic and economic burden of generalized anxiety disorder in North America and Europe. Journal of affective disorders, 140(2), 103-112.

[16] Hoffman, D. L., Dukes, E. M., Wittchen, H. U. (2008). Human and economic burden of generalized anxiety disorder. Depression and anxiety, 25(1), 72-90.

[17] Toghanian, S., DiBonaventura, M., Järbrink, K., Locklear, J. C. (2014). Economic and humanistic burden of illness in generalized anxiety disorder: an analysis of patient survey data in Europe. ClinicoEconomics and outcomes research: CEOR, 6, 151-163. 
[18] Andlin-Sobocki, P., Wittchen, H. U. (2005). Cost of anxiety disorders in Europe. European Journal of Neurology, 12(s1), 39-44.

[19] Simon, G. E. (2003). Social and economic burden of mood disorders. Biological psychiatry, 54(3), 208-215.

[20] Paykel, E. S., Brugha, T., Fryers, T. (2005). Size and burden of depressive disorders in Europe. European neuropsychopharmacology, 15(4), 411-423.

[21] Sobocki, P., Lekander, I., Borgström, F., Ström, O., Runeson, B. (2007). The economic burden of depression in Sweden from 1997 to 2005. European Psychiatry, 22(3), 146-152.

[22] Thomas, C. M., Morris, S. (2003). Cost of depression among adults in England in 2000. The British Journal of Psychiatry, 183(6), 514-519.

[23] Friemel, S., Bernert, S., Angermeyer, M. C., König, H. H. (2005). Die direkten Kosten von depressiven Erkrankungen in Deutschland. Psychiatrische Praxis, 32(03), 113-121.

[24] Berto, P., D'Ilario, D., Ruffo, P., Virgilio, R. D., Rizzo, F. (2000). Depression: cost-ofillness studies in the international literature, a review. The Journal of Mental Health Policy and Economics, 3(1), 3-10.

[25] Wang, P. S., Simon, G., \& Kessler, R. C. (2003). The economic burden of depression and the cost-effectiveness of treatment. International journal of methods in psychiatric research, 12(1), 22-33.

[26] Pini, S., de Queiroz, V., Pagnin, D., Pezawas, L., Angst, J., Cassano, G. B., Wittchen, H. U. (2005). Prevalence and burden of bipolar disorders in European countries. European Neuropsychopharmacology, 15(4), 425-434.

[27] Das Gupta, R., Guest, J. F. (2002). Annual cost of bipolar disorder to UK society. The British Journal of Psychiatry, 180(3), 227-233.

[28] Runge, C., \& Grunze, H. (2004). Jährliche Krankheitskosten bipolarer Störungen in Deutschland. Der Nervenarzt, 75(9), 896-903.

[29] Kleine-Budde, K., Touil E, Moock, J., Bramesfeld, A., Kawohl, W., Rössler, W.(2013). Cost of illness for bipolar disorder: a systematic review of the economic burden. Bipolar Disorders 2013: Published by John Wiley \& Sons Ltd.

[30] Fajutrao, L., Locklear, J., Priaulx, J., \&Heyes, A. (2009). A systematic review of the evidence of the burden of bipolar disorder in Europe. Clinical Practice and Epidemiology in Mental Health, 5(3), doi:10.1186/1745-0179-5-3

[31] Lindström, E., Widerlöv, B., von Knorring, L. (1997). The ICD-10 and DSM-IV diagnostic criteria and the prevalence of schizophrenia. European psychiatry, 12(5), 217-223. 
[32] Millier, A., Schmidt, U., Angermeyer, M. C., Chauhan, D., Murthy, V., Toumi, M., Cadi-Soussi, N. (2014). Humanistic burden in schizophrenia: A literature review. Journal of psychiatric research, 54, 85-93.

[33] Kitchen, H., Rofail, D., Heron, L., Sacco, P. (2012). Cognitive impairment associated with schizophrenia: a review of the humanistic burden. Advances in therapy, 29(2), 148-162.

[34] Awad, A. G., \&Voruganti, L. N. (2008). The burden of schizophrenia on caregivers. Pharmacoeconomics, 26(2), 149-162.

[35] Beary, M., Hodgson, R., \&Wildgust, H. J. (2012). A critical review of major mortality risk factors for all-cause mortality in first-episode schizophrenia: clinical and research implications. Journal of Psychopharmacology, 26(5 suppl), 52-61.

[36] Morden, N. E., Lai, Z., Goodrich, D. E., MacKenzie, T., McCarthy, J. F., Austin, K., Welsh, D.E., Bartels, S., Kilbourne, A. M. (2012). Eight-year trends of cardiometabolic morbidity and mortality in patients with schizophrenia. General hospital psychiatry, 34(4), 368-379.

[37] Laursen, T. M., Munk-Olsen, T., Vestergaard, M. (2012). Life expectancy and cardiovascular mortality in persons with schizophrenia. Current opinion in psychiatry, 25(2), 83-88.

[38] Kelly, D. L., McMahon, R. P., Liu, F., Love, R. C., Wehring, H., Shim, J. C., Warren, K.R., Conley, R. R. (2010). Cardiovascular Disease Mortality in Chronic Schizophrenia Patients Treated with Clozapine. The Journal of clinical psychiatry, 71(3), 304-3011.

[39] Hor, K., \& Taylor, M. (2010). Review: Suicide and schizophrenia: a systematic review of rates and risk factors. Journal of Psychopharmacology, 24(4 suppl), 81-90.

[40] Bushe, C. J., Taylor, M., Haukka, J. (2010). Review: Mortality in schizophrenia: a measurable clinical endpoint. Journal of Psychopharmacology, 24(4 suppl), 17-25.

[41] Knapp, M., Mangalore, R., Simon, J. (2004). The global costs of schizophrenia. Schizophrenia bulletin, 30(2), 279-293.

[42] Oliva-Moreno, J., López-Bastida, J., Osuna-Guerrero, R., Montejo-González, A. L., \& Duque-González, B. (2006). The costs of schizophrenia in Spain. The European Journal of Health Economics, 7(3), 179-184.

[43] Mangalore, R., \& Knapp, M. (2007). Cost of schizophrenia in England. Journal of Mental Health Policy and Economics, 109(1), 23-41.

[44] WHO (2014). Global status report on alcohol and health. Luxembourg.

[45] Andlin-Sobocki, P., Rehm, J. (2005). Cost of addiction in Europe. European Journal of Neurology, 12(s1), 28-33. 
[46] Baumberg, B. (2006). The global economic burden of alcohol: a review and some suggestions. Drug and alcohol review, 25(6), 537-551.

[47] Jane-Llopis, E. V. A., \&Matytsina, I. (2006). Mental health and alcohol, drugs and tobacco: a review of the comorbidity between mental disorders and the use of alcohol, tobacco and illicit drugs. Drug and alcohol review, 25(6), 515-536.

[48] Rehm, J., Mathers, C., Popova, S., Thavorncharoensap, M., Teerawattananon, Y., Patra, J. (2009). Global burden of disease and injury and economic cost attributable to alcohol use and alcohol-use disorders. The Lancet, 373, 2223-2233.

[49] Room, R., Babor, T., \&Rehm, J. (2005). Alcohol and public health. The lancet, 365, 519-530.

[50] Boden, J.M., Fergusson, D.M., Horwood, L. J. (2013). Alcohol misuse and criminal offending: Findings from a 30-year longitudinal study, Drug and Alcohol Dependence, 128(1-2), 30-36.

[51] Rehm, J., Room, R., van den Brink, W., \& Jacobi, F. (2005). Alcohol use disorders in EU countries and Norway: an overview of the epidemiology. European Neuropsychopharmacology, 15(4), 377-388.

[52] Laramée, P., Kusel, J., Leonard, S., Aubin, H. J., François, C., Daeppen, J. B. (2013). The economic burden of alcohol dependence in Europe. Alcohol and alcoholism, 48(3), 259-269.

[53] Jarl, J., Johansson, P., Eriksson, A., Eriksson, M., Gerdtham, U. G., Hemström, Ö.,Selin, K.H., Lenke, L., Ramstedt, M., Room, R. (2008). The societal cost of alcohol consumption: an estimation of the economic and human cost including health effects in Sweden, 2002. The European Journal of Health Economics, 9(4), 351-360.

[54] Konnopka, A., \& König, H. H. (2007). Direct and indirect costs attributable to alcohol consumption in Germany. Pharmacoeconomics, 25(7), 605-618.

[55] Laireiter, A. R., Messer, R., \& Baumann, U. (2008). Alt und ohne Hilfe-Zur psychosozialen Versorgung alter Menschen. Zeitschrift für Gerontopsychologie \&-psychiatrie, 21(1), 5-9.

[56] Wancata, J., Kaiser, G. (2008). Dimensionen der psychosozialen Versorgung alter Menschen. Zeitschrift für Gerontopsychologie \&-psychiatrie, 21(1), 11-19.

[57] Berr, C., Wancata, J., Ritchie, K. (2005). Prevalence of dementia in the elderly in Europe. European neuropsychopharmacology, 15(4), 463-471.

[58] Jönnson, L., Wimo, A. (2009). The Cost of Dementia in Europe. A Review of the Evidence, and Methodological Considerations. Pharmacoeconomics, 27(5), 391-403.

[59] Connolly, S., Gillespie, P., O'Shea, E., Cahill, S., Pierce, M. (2014). Estimating the economic and social costs of dementia in Ireland. Dementia, 13(1), 5-22. 
[60] Érsek, K., Kovács, T., Wimo, A., Kárpati, K., Brodszky, V., Péntek, M., Jönsson, L. Gustavvson, A. McDaid, D., Kenigsberg, P.E., Valtonen, H., Gulácsi, L. (2010). Costs of dementia in Hungary. The journal of nutrition, health \& aging, 14(8), 633-639.

[61] Wimo, A., Jönsson, L., Gustavsson, A., McDaid, D., Ersek, K., Georges, J., Gulacsi, L., Karpati, K., Kenigsberg, P., Valtonen, H. (2011). The economic impact of dementia in Europe in 2008-cost estimates from the Eurocode project. International journal of geriatric psychiatry, 26(8), 825-832.

[62] Beecham, J. (2014). Annual Research Review: Child and adolescent mental health interventions: a review of progress in economic studies across different disorders. Journal of Child Psychology and Psychiatry, 55(6), 714-732.

[63] Rowland, A. S., Lesesne, C. A., \& Abramowitz, A. J. (2002). The epidemiology of attention-deficit/hyperactivity disorder (ADHD): A public health view. Mental retardation and developmental disabilities research reviews, 8(3), 162-170.

[64] Schöffski, O., Sohn, S., Happich, M. (2008). Die gesamtgesellschaftliche Belastung durch die hyperkinetische Störung (HKS) bzw. Aufmerksamkeitsdefizit-/Hyperaktivitätsstörung (ADHS). Das Gesundheitswesen, 70(7), 398-403.

[65] De Ridder, A., De Graeve, D. (2006). Healthcare use, social burden and costs of children with and without ADHD in Flanders, Belgium. Clinical drug investigation, 26(2), 75-90.

[66] Le, H. H., Hodgkins, P., Postma, M. J., Kahle, J., Sikirica, V., Setyawan, J., Haim-Erder, M., Doshi, J. A. (2013). Economic impact of childhood/adolescent ADHD in a European setting: the Netherlands as a reference case. European child \& adolescent psychiatry, 1-12.

[67] Tcheremissine, O. V., Lieving, L. M. (2006). Pharmacological aspects of the treatment of conduct disorder in children and adolescents. CNS Drugs, 20, 549-565.

[68] Ewest, F., Reinhold, T., Vloet, T. D., Wenning, V., Bachmann, C. J. (2013). Durch Jugendliche mit Störungen des Sozialverhaltens ausgelöste Krankenkassenausgaben. Kindheit und Entwicklung, 22(1), 41-47.

[69] Romeo, R., Knapp, M., \& Scott, S. (2006). Economic cost of severe antisocial behaviour in children - and who pays it. The British Journal of Psychiatry, 188(6), 547-553.

[70] Knapp, M., Romeo, R., \& Beecham, J. (2009). Economic cost of autism in the UK. Autism, 13(3), 317-336.

[71] Barrett, B., Byford, S., Sharac, J., Hudry, K., Leadbitter, K., Temple, K., Aldred, C., Slonims, V., Green, J. (2012). Service and wider societal costs of very young children with autism in the UK. Journal of autism and developmental disorders, 42(5), 797-804.

[72] Snell, T., Knapp, M., Healey, A., Guglani, S., Evans-Lacko, S., Fernandez, J. L., Meltzer, H., Ford, T. (2013). Economic impact of childhood psychiatric disorder on public 
sector services in Britain: estimates from national survey data. Journal of child psychology and psychiatry, 54(9), 977-985.

[73] Heitzmann, K., Österle, A. (2008).Lange Traditionen und neue Herausforderungen: Das österreichische Wohlfahrtssyste In: Schubert, K., Hegelich, S., Bazant, U. (eds). Europäische Wohlfahrtssysteme. Ein Handbuch. VS Verlag, Wiesbaden, 47-70.

[74] Badelt C, Österle A. (2001). Grundzüge der Sozialpolitik. Spezieller Teil: Sozialpolitik in Österreich. 2nd ed., Manz, Wien

[75] Statistik Austria, Gesundheitsausgaben in Österreich. online (access 05.07.2014) http://www.statistik.at/web_de/statistiken/gesundheit/gesundheitsausgaben/ index.html

[76] GesundheitÖsterreich GmbH (2010). The Austrian health Care System. Key facts. Österreichisches Bundesministerium für Gesundheit,Wien

[77] Arbeitsmarktservice (2014). Rund um Arbeit und Behinderung. EineBroschürefürArbeitsuchende Menschen mitLernschwierigkeiten und/oder Behinderung. Wien

[78] Meise U, Wancata J, Hinterhuber H. Die Entwicklung der psychiatrischen Versorgung in Österreich. In: Rittmannsberger, H, Wancata, J. (eds.) Der österreichische Schizophreniebericht. Im Auftrag des Bundesministeriums für Gesundheit, Familie und Jugend, Linz, 2008, 134-145.

[79] Elgeti, H. (2013). Vorarlberger Psychiatriebericht. Im Auftrag des Amtes der Vorarlberger Landesregierung. Bregenz.

[80] Gesundheitsplattform Steiermark (2013). Psychiatriebericht 2012. Plattform Psyche zur psychosozialen Versorgung in der Steiermark. Online (access 10.07.2014) http:// www.plattformpsyche.at/Documents/psychiatriebericht2012.pdf

[81] Katschnig, H., Denk, P., Scherer, M. (2004). Österreichischer Psychiatriebericht 2004.Analysen und Daten zur psychiatrischen und psychosozialen Versorgung der österreichischen Bevölkerung. Im Auftrag des Bundesministeriums für Gesundheit und Frauen, Wien.

[82] Gesundheit Österreich GmbH (2012). Österreichischer Strukturplan Gesundheit 2012 inklusive Großgeräteplan. Im Auftrag der Bundesgesundheitsagentur. Bundesministerium für Gesundheit. Wien.

[83] Hauptverband der österreichischen Sozialversicherungsträger (2012). Strategie psychische Gesundheit. Krankheit verhindern-Versorgung verbessern-Invalidität verringern. Salzburg.

[84] Kapusta, N. (2010). Aktuelle Daten und Fakten zur Zahl der Suizide in Österreich. Wien.

[85] Kapusta, N., Sonnecke, G. (2012). Suizide in Österreich: ein Update zur Entwicklung und aktueller Stand. neuropsychiatrie, 26(3), 103-105. 
[86] Watzka, C. (2012). Soziale Bedingungen von Selbsttötungen in Österreich. Eine Übersicht zu Risiko-und Schutzfaktoren. neuropsychiatrie, 26(3), 95-102.

[87] Bundesministerium für Gesundheit (2011). SUPRA-Suizidprävention Austria. Wien, 2011.

[88] Uhl, A., Bachmayer, S, Puhm, A., Strizek, J., Kobrna, U, Musalek, M. (2011). Handbuch Alkohol-Österreich. Statistiken und Berechnungsgrundlagen. Bundesministerium für Gesundheit, Wien.

[89] Zechmeister I. (2005). Mental health care financing in the process of change: challenges and approaches for Austria. Lang, Frankfurt am Main ; Wien [u.a.] .

[90] Österreichisches Institut für Gesundheitswesen (2010). Versorgung mit Psychotherapie. Eine Iststand-Erhebung mit einem Sonderkapitel zu Psychopharmaka. Eine Studie im Auftrag des Bundesministeriums für Gesundheit, Wien.

[91] Thun-Hohenstein, L. (2008). Die Versorgungssituation psychisch auffälliger und kranker Kinder und Jugendlicher in Österreich. Kindermedizin-Werte versus Ökonomie. Springer, Wien, 163-173.

[92] Thun-Hohenstein, L (2011). Kinder-und jugendpsychiatrische Versorgung in Österreich-ein Update. In: Kerbl, R., Thun-Hohenstein, L., Damm, L., \& Waldhauser, F. (Eds.). Kinder und Jugendliche im besten Gesundheitssystem der Welt. 4. Jahrestagung Politische Kindermedizin 2010, Springer, Wien, 83-90.

[93] Berger E, Aichhorn W, Friedrich MH, Fiala-Preinsperger, S., Leixnering, W., Mangold, G., Spiel, B., Tatzer, E., Thun-Hohenstein, L. (2006). Kinder-und Jugendpsychiatrische Versorgung in Österreich. Neuropsychiatrie 20(2), 86-90.

[94] Hauptverband der österreichischen Sozialversicherungsträger, Salzburger Gebietskrankenkasse (2011). Analyse der Versorgung psychisch Erkrankter. Projekt „Psychische Gesundheit. Abschlussbericht. Wien/ Salzburg.

[95] Wancata, J., Sobocki, P., Katschnig, H. (2007). Die Kosten von "Gehirnerkrankungen" in Österreich im Jahr 2004. Wiener klinische Wochenschrift, 119(3-4), 91-98.

[96] Haberfellner, E.M. (2008): Kosten der Schizophrenie. In: Rittmannsberger, H., Wancata, J. (Hrsg.): Österreichischer Schizophreniebericht 2008, Bundesministerium für Gesundheit, Wien, 191-198.

[97] Czypionka, T., Pock, M., Röhrling, G., Sigl, C. (2013). Volkswirtschaftliche Effekte der Alkoholkrankheit. Eine ökonomische Analyse für Österreich. Research Report, Institute for Advanced Studies, Vienna.

[98] Yang, B., Lester, D. (2007) Recalculating the Economic Cost of Suicide. Death Studies, 31(4), 351-361.

[99] EUROSTAT (2014). Ausgaben der Leistungserbringer der Gesundheitsversorgung nach Kostenträgern der Gesundheitsversorgung-EUR, Einheiten Landeswährung, 
KKS [hlth_sha3m] . http://appsso.eurostat.ec.europa.eu/nui/submitViewTableAction.do [access 04.09.2014]

[100] EUROSTAT (2014). Bevölkerung am 1. Januar nach Alter und Geschlecht [demo_pjan] http://appsso.eurostat.ec.europa.eu/nui/show.do?dataset=demo_pjan\&lang=de [access 04.09.2014]

[101] Knapp, M., King, D., Healey, A., \& Thomas, C. (2011). Economic outcomes in adulthood and their associations with antisocial conduct, attention deficit and anxiety problems in childhood. Journal of Mental Health Policy and Economics, 14(3), 137-147. 
